\title{
Investigating an Online Course for Player Psychosocial Development in Elite Sport (Professional Football)
}

\section{Lee Richardson ${ }^{1}$, Ricardo Lugo ${ }^{2}$ and Andrea Firth ${ }^{3}$}

${ }^{1}$ Aim-For; ${ }^{2}$ Department of Health Welfare and Organization, Østfold University College, Halden, Norway. ${ }^{3}$ UCFB, Department of Sport Psychology UCFB, Wembley, London UK; Headgame London UK.

Corresponding author: Richard Lugo

E-mail: Ricardo.G.Lugo@hiof.no

Faculty of Health \& Welfare, Østfold University College, Halden, Norway

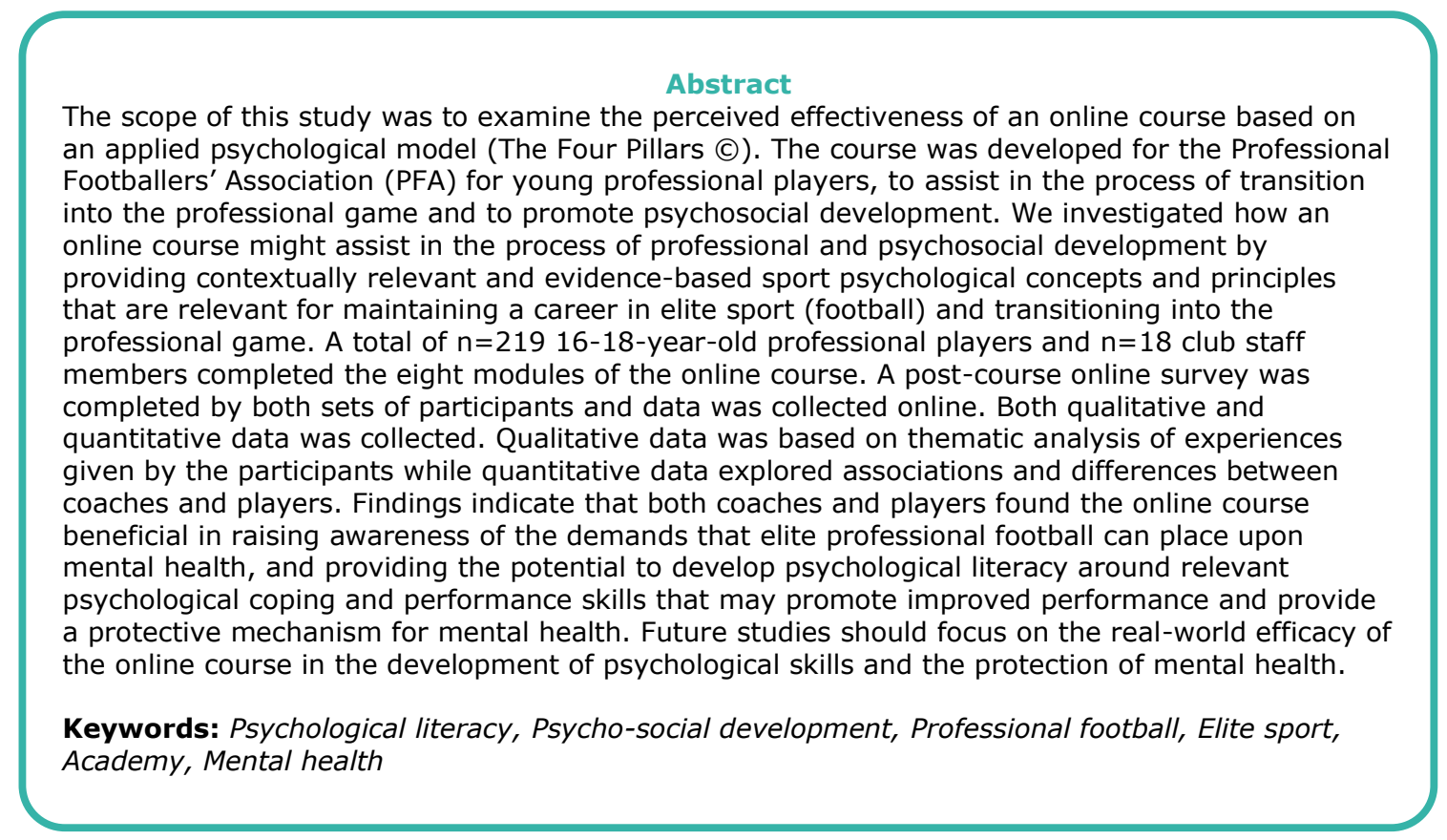

Concerns have been raised regarding current issues in athlete mental health and the lack of help-seeking behaviours (Steinfeldt \& Steinfeldt, 2012). There is a need, therefore, for greater education amongst athletes and athletic staff to increase knowledge of mental health issues and their impact on performance and long-term athlete development (Schinke et al., 2018). Professional footballers have specifically been identified amongst the higher-risk populations in relation to depression and anxiety (Blakelock et al., 2016; Miller et al., 2015), identity disruption (Brown \& Potrac, 2009), identity foreclosure (Brownrigg et al., 2012; Gearing, 1999; Mitchell et al., 2014), and gambling, alcohol and drug addiction (Gouttebarge et al., 2016), which are all recognised as significant issues amongst current and former players. Given these current concerns, it is important to allow athletes the means to recognise and address mental health issues in order for them to adopt and improve coping skills and ultimately maintain good mental health. One proposed method of improving coping skills is by increasing knowledge of potential mental health challenges during a professional career and behaviours that may provide protection against the development of problematic issues via athlete education programmes (Henriksen et al., 2020; MacIntyre et al., 2017; Schinke et al., 2018; Taylor \& Hulme, 2015).

To improve athlete education, the Professional Football Association (PFA), the union representing professional footballers in England and Wales, began an initiative in 2014 which focused on addressing mental health and other relevant issues within the sport. The online course of this study is currently available to all Premier League and Football League clubs, to benefit young professional players aged 16 years and over, and their key support group: coaches and parents. This research paper addresses player and coach perception on the efficacy of the course. By understanding such perceptions, the research will highlight the practical relevance, if any, of this course to the PFA that is the main organisation responsible for the care of elite UK players. It seeks to provide one method of assisting the PFA in supporting its athletes by providing mental health educational standardization within football academies.

The conceptual framework underpinning this study has elements which are based around pedagogical frameworks including experiential learning theory (Kolb \& Kolb, 2009) 
in which players can identify with scenario-based learning (Blackburn, 2015). Experience is also gained through the use of mentoring, also known to be an effective means of knowledge acquisition (Hilsdon, 2014). If conducted well, virtual interactive teaching is effective (Francescucci \& Rohani, 2019), therefore the course includes multimedia resources and gamification via online learning. Examination of the efficacy of the course will add to the limited existing research into online programmes aimed at promoting the prevention of psychological distress in young professional football players.

The psychological and physical demands athletes often experience can have a detrimental effect upon athlete enjoyment, engagement, performance, and well-being, contributing to negative outcomes such as overtraining and burnout (Gould et al., 1993), disordered eating (SundgotBorgen \& Torstveit, 2004), damaged self-esteem, and affective disorders such as anxiety and depression (FraserThomas \& Côté, 2009; Krane et al., 1997). Research suggests it is important to understand how relevant social and contextual factors shape both the positive and negative experiences of athletes in sporting environments (Smith \& Smoll, 2002). The number of current players asking the PFA for help with mental health issues rose by more than $500 \%$ between 2016 and 2018, according to the PFA counselling website (PFA, 2021). Elite athletes experience a comparable risk of high prevalence mental disorders in relation to the general population with increased risk factors for elite athletes who are injured, experiencing performance difficulties, approaching retirement or in retirement (Rice et al., 2016).

The need for educating athletes in mental health issues and associated coping strategies are based around the fact that an internal locus of control (Wallston \& Wallston, 1981) may allow players to become more adept at self-management and acquire and hone active coping strategies (Crocker, 1992), thus lowering the burden on external resources.

Generally, there is an apparent need to increase the awareness of mental health issues as there are deficiencies in public knowledge in how to prevent mental dysfunction and the potential of recognising the onset of mental health disorders, understanding of how to seek treatment and gain help, how to self-help milder mental health issues and how to support others with mental health issues (Jorm, 2000). In order to raise awareness, the PFA has provided the Safety Net (c) for members since 2014 along with the online course, which has been developed based on growing evidence that online interventions are supportive of mental health (Hollis et al., 2017).

\section{PFA Psychological Support - Current Mental Health Provision}

PFA membership begins at the age of sixteen when young players leaving educational environments report for pre-season training, normally in preparation to begin an initial two-year training period as a trainee professional, entitling them to a life-time membership of the PFA. Membership includes access to the mental health crisis helpline, 24/7/365, comprising of a national network of counsellors, a residential rehabilitation centre (Sporting Chance), an online mental health and well-being educational platform and a self-assessment portal, the PFA Safety Net (C).

Other organisations have some influence and responsibility over the development of young players in the English professional game including the English Football League (EFL) and its educative wing, the League Football Education (LFE), as well as the Premier League, which in 2013 introduced the Elite Player Performance Program
(EPPP) in line with recommendations from Ged Roddy in 2012. The implementation of the EPPP throughout the football pyramid resulted in assessment of each club and placement into a tiering system based on the quality and appropriateness of each clubs young player development program. Part of the PFA rationale for the development of the course was the perceived inconsistent delivery of psychoeducation provided to its members throughout many academies.

The online course presented in this research was developed in response to the current evidence around mental health outcomes and the need for psychological development programs offered by professional football clubs. Furthermore, the PFA has taken the step to investigate the potential of providing a psychological performance and well-being program to aid the 'transitioning' entrées into the professional game. The course was first implemented as a pilot study involving four clubs (one in each tier category 1, 2, 3 and 4) in February 2019. In June of 2019 the initial roll-out of the PFA course was launched and, as of December 2019, ninety-two professional clubs have engaged with the project.

\section{Conceptual Model of Education and Pedagogical Approach}

The underpinning pedagogy of the online course is based on the ten principles for effective pedagogy outlined by James and Pollard (2011) where effective pedagogy must: 1) equip learners for life, 2) use valued forms of knowledge, 3) recognise the importance of prior experience, 4) use scaffolding, 5) have correct assessments, 6) promote active engagement, 7) foster individual and social processes and outcomes, 8) recognise informal learning, 9) depend on the learning of all those who support the learning of others, and 10) demand consistent policy framework with support for learning. These ten principles form the underlying theoretical standpoint used to establish the learning materials for the course. For example, one of the focuses of the PFA course is to provide users with an insight into the contextual challenges of a career in sport. As such, the course is set out in modules addressing psychological principles as competencies to aspire to with Outcome-Based Education (OBE) objectives set out throughout the learning journey. The course has eight modules addressed as competencies that promote learning processes in performance, well-being and good mental health with psychological conceptual information.

Scenario-Based Learning Interactive (SBL Interactive) is another main pedagogical tool utilised in the course and has potential benefits because scenario-based learning is more effective than reflective learning in imparting knowledge (Hursen \& Fasli, 2017) which also is integrated in the ten principles described above. SBL Interactive is an easy-to-use, multi-disciplinary e-learning tool for creating self-paced learning activities (Blackburn, 2015). Such evidence indicates the inclusion of OBE and SBL Interactive in the course as appropriate learning tools. The course also embedded multimedia resources designed to enhance learner engagement that uses case formulations, uses real life examples from current and previous professional athletes and coaches (Leacock \& Nesbit, 2007). To measure the effectiveness of the course the Learning Object Review Instrument (LORI) (Leacock \& Nesbit, 2007) was adopted. This course evaluation aid enables course users to create reviews consisting of ratings and comments on nine dimensions. 


\section{Aims}

Based on the previous findings of the prevalence of mental health challenges in professional footballers, the online course was aimed at giving psychoeducation on mental health coping strategies through knowledge and case descriptions. The aim for this research is to examine the efficacy of an online course designed to help athletes cope with the inherent stressors within football.

\section{Methods}

Exploratory design (Creswell \& Báez, 2020) strategies were utilised, and qualitative online surveys were completed by the participants. The main theoretical model underpinning the research question focused on a dual hypothesis: that the online course might provide a mechanism to promote the development of raised awareness, meta-cognition, psychological literacy and transferable skills such as mindfulness, and help-seeking in a vulnerable population prior to entry into a notoriously challenging environment (Nesti, 2011).

\section{Online Survey}

A priori decision was made to implement an online survey that was undertaken upon completion of the online course by both sets of participants and designed to obtain both qualitative responses for deductive thematic analysis as well as providing descriptive quantitative data. The survey was implemented to ascertain the opinions of professional youth trainees $(n=218)$ and coaches/academy professionals $(n=17)$ from 33 Premier League and English Football League clubs. The youth trainees are elite trainees and professionals where some have professional contracts and others are on trainee programs intended to facilitate professional contracts at their current club. Participants were recruited from all but 2 premier league clubs and 1 Football league club. The participants and club staff were enlisted prior to the completion of the course in order to gain consent to complete the survey as part of this study. The club staff and players were given the option of completing the survey or to decline. All the players who took the course completed the survey, whereas around $50 \%$ of the coach/academy staff did so ( 17 from 33 clubs). The survey questionnaire consisted of two parts. In the first part participants were asked four questions related to personal 'Development', ease of course 'Access', the usefulness of the 'Content' of the course, and ease with which they could 'Navigate' the course content. These questions were scored on a 3-point scale (positive, negative, not sure). These questions were used to quantify the meaning and the user experience of the course. The first section of the survey was analysed through nonparametric analyses.

To analyse the multimedia resources and scenariobased learning with outcome-based objectives surrounding relevant psychological principles or competencies, an online Learning Management System (LMS, Absorb https://www.absorblms.com/) was integrated into the online modules. The second part of the questionnaire assessed the qualitative experiences of the participants in (a) subjective preferred aspects of the course and (b) ascertaining how they believed the course might be improved. The second part of the survey was evaluated using the Learning Object Review Instrument (LORI) developed by Nesbit et al. (2004), validated by Akpinar (2009) and available via Vargo et al. (2003). A deductive thematic analysis developed by Braun and Clarke (2006) was used to analyse the coding of participant responses. The coded items were then matched to the LORI themes. Responses that did not meet the criteria of coding matching the LORI framework were also separately analysed by thematic analysis and were assigned to non-LORI-themed categories. The primary goal of LORI is to balance assessment validity with the efficiency of the evaluation process. It enables researchers to create reviews consisting of ratings and comments on nine dimensions.

- Content Quality to measure veracity, accuracy, balanced presentation of ideas, and appropriate level of detail

- Learning Goal Alignment to assess alignment among learning goals, activities, assessments, and learner characteristics

- Feedback and Adaptation based on content or feedback driven by differential learner input or learner modeling

- Motivation; its ability to motivate and stimulate the interest or curiosity of an identified population of learners

- Presentation Design that includes visual and auditory information for enhanced learning and efficient mental processing

- Interaction Usability that gives ease of navigation, predictability of the user-interface (UI), and the quality of UI help features

- Accessibility to support for learners with disabilities

- Reusability; it's ability to port between different courses or learning contexts without modification

- Standards Compliance that adherence to international standards and specification

Accessibility and Standards Compliance will not be used for this study because these LORI factors do not apply to this module. This online course is accessible to any participant and there are no international standards set for such courses.

\section{Procedure}

The online course was carried out over four months from June 2019 to September 2019; however, a standardised timeframe for onset and completion of the course was not established. Instead, each club was given autonomy to determine the pace at which it would enable access to the players and permit engagement during work time. The course consisted of eight modules and an introductory module. The course content was developed in line with the Four Pillars model of psychology developed by Richardson. The Four Pillars model encompasses the idea of four fundamental human attributes, as proposed by Reiter (1987), thought to be crucial in performance and everyday psychological function, namely: perception, motivation, cognition and emotion. In order to promote more accessible language for sports performers, the author of the Four Pillars model utilised Awareness (Perception), Attitude (Motivation), Agility (Cognition) and Adjustment (Emotion) as terms to represent the Four Pillars. The online course consists of two sub-sections of relevance to each Pillar, which have been deemed by the author, Richardson, to be supporting concepts that represent competencies to be acquired for performance, mental health and well-being benefit. Each of the subsections represent the online course material, namely: Awareness = Identity \& Connection, Attitude $=$ Values \& Action, Agility $=$ Readiness \& Intelligence, and Adjustment = Flexibility \& Resilience. The course takes approximately 15-30 minutes to complete per module. 


\section{Data Collection and Data Analysis}

Questionnaires were completed online post-course. Descriptive data were analysed using JASP v0.13.1. Qualitative data were analysed using the deductive thematic analysis guidelines established by Braun and Clarke (2006). Deductive thematic analysis (Clarke et al., 2015; Terry et al., 2017) and descriptive quantitative analysis of the themes were conducted on the responses obtained to questions 1 and 2 and then mapped on to the LORI. For the purposes of the deductive latent thematic qualitative analysis of this research, in order to classify responses from the research participants, it was apparent that not all nine themes of the LORI framework were applicable and it was decided that the first seven conceptual items in the LORI table should be used. Item 8, reusability, and item 9, standards compliance, were not considered relevant by the principal researcher of this study. Instead, applicability (the quality of being relevant or appropriate) was used. No category (for items that are outside of any category or have no usable data) and non-specific positive versus non-specific negative were introduced as additional categories to allow for a more accurate summary of the data.

Seven of the nine themes of the LORI framework were utilised to map the themes that arose from the codes from the analysis (Accessibility and Standards were not applicable for this research). A spreadsheet was utilised for the thematic analysis. The thematic analysis followed the steps described by Terry et al. (2017) including; familiarization, generating codes, constructing themes, reviewing, and producing the report. The data emerged from the responses obtained for each question (positive and negative experiences with the course). Familiarity with the data (step 1) and code generation (step 2) was done with spreadsheets. Responses that did not fall under the LORI themes were coded as no response or other. The LORI categories were used as overarching themes (step 3). The data was then reviewed with supervisors not involved in the project development or data collection and the current manuscript was produced.

The understanding of validity has always been a focus of quantitative research, whereas within qualitative research it has been lacking. But validity in qualitative research and how it is pertinent has been recently developed by Flick (2018). Flick states that validity has to encompass how the data is produced and presented while including eight specific focuses (Tracy, 2010, p. p. 840): (1) a worthy topic, (2) rich rigor, (3) sincerity, (4) credibility, (5) resonance, (6) significant contribution, (7) ethics, and (8) meaningful coherence. This research topic is worthy due to its relevance in training both players and coaches in identifying and maintaining mental health in elite sports. Mental health has gained more attention in recent times but has always been an issue. Good mental health is not only necessary for all people, but also has been shown to help athletic performance (Donohue et al., 2018; Gorczynski et al., 2019).

This research was done with rich rigor. This focus involves a rich complexity of information that arises from a 'requisite variety' (Weick, 2007, p. p. 16) of sources. The training program was developed by professionals including experts and stakeholders, and the follow-up LORI analysis gives quantitative aspects of experiences; the thematic analysis will incorporate subjective experiences into the final picture.

While the principal investigator has previous experience as a professional footballer, the research was done with sincerity, i.e. the "research is marked by honesty and transparency about the researcher's biases, goals, and foibles as well as about how these played a role in the methods, joys, and mistakes of the research" (Weick, 2007, p. 842). This sincerity is shown through self-reflexivity of the researcher's own involvement in the research and its transparency. While the learning module was based on experiences and interactions with experts and stakeholders, the data was collected from individuals ranging from novices to experts and the data was analyzed objectively giving it credibility. The resonance focus refers to the research's ability to connect with an audience through aesthetic merit, evocative writing, formal generalizations, and transferability (Weick, 2007). This entails the use of clear language that is understandable to the audience while omitting unnecessary jargon or technical explanations (aesthetic merit). The findings from the course evaluation and the experiences with the module come from participants with different backgrounds and from different geographical locations, supporting the generalizability and transferability of the findings.

This research also provides a significant contribution to this developing domain. This contribution is achieved on four levels (Tracy, 2010): (1) theoretical, (2) heuristic, (3) practical, and (4) methodological significance. This research develops theoretically significant contributions by developing new deliveries that support good psychosocial development and positive mental health. The novelty of the content and delivery allows for heuristic significance since it allows future development to include aspects not yet identified, and practical significance by supplying information that helps develop coping strategies (Tracy, 2010). The evaluation approach, combining thematic analysis and LORIs, provides a template for similar interventions making the study methodologically significant.

The ethical focus of qualitative research validity spans dilemmas faced by researchers concerning design, field relations when in contact with people, data handling, analysis and presentation (Flick, 2007). This research used standard online deliveries accessible to any participant; it used domain professionals (footballers) for reenactments so that participants could relate to the scenarios, maintained anonymity, and the data was objectively analyzed and presented in collaboration with other researchers who were not directly involved in the project. Finally, a meaningful coherence is attained when research achieves its stated purpose, accomplishes what it supports to be about, uses methods and representation practices that have support in theories and paradigms, and is able to relate to the current literature (Tracy, 2010), which are all part of the communicative validity of the research (Flick, 2018).

\section{Ethical Approval}

Ethical approval was gained via the University Campus of Football Business (UCFB) ethics committee. As the participants were under 18 years of age, written informed consent was obtained from a parent and assent was obtained directly from the participant. The participants were required to opt in, and the data of those who chose not to do so were excluded from the research. The collection and storage of data, especially that which could identify the participants, was firstly anonymised using a pseudonym/code and kept in a password protected/encrypted file. Both sets of participants were advised that the survey was optional and that refusal to take part was acceptable. Participants were also advised that their data would be anonymised in line with data protection laws (GDPR). 


\section{Results}

\section{Online Survey}

A total of 236 participants ( $N_{\text {players }}=218$ ) completed the first part of the online survey that assessed the quantitative aspects of personal meaning of taking the course and user experience. The assessment of the modules is given in table 1 . While players and coaches did not significantly differ on the four measurements of development $(U=1637, p=.135, R B C=.121)$, access $(U$ $=1986, p=.571, R B C=.067)$, content $(U=1559, p=$ $.071 R B C=.163)$, and navigate $(U=1997.5, p=.532$, $R B C=.073$ ), there were reported differences. Players reported more positive meaning for personal development $(89.5 \%$ vs $76.5 \%)$ and content usefulness $(92.7 \%$ vs $88.2 \%$ ), whereas coaches reported more positive experiences for access (76.5\% vs $69.4 \%$ ) and navigation $(76.5 \%$ vs $70.3 \%)$. The non-significant findings can be attributed to the uneven numbers of respondents in each group (218 vs 18 ).

Of the total responses given for the online survey in all four categories (944 responses), $19.6 \%$ (185) of the responses were not positive (not sure and not useful). A composite score for all four items was calculated by assigning the values as easy/helpful: 1 ; not sure: 2 ; not helpful/not easy: 3 , for a total score of 4 to 12 . Then the total scores were divided according to the responses (easy, not sure, not easy). A total of $68.6 \%$ of the respondents reported the course as helpful/easy, $19.9 \%$ were not sure and $11.4 \%$ rated the course as not helpful/not easy. These groups will be used in the analysis of the number of comments, both positive and negative, from the thematic analysis of the LORI.

Table 1: Assessment of Modules

\begin{tabular}{llcc}
\hline \multirow{3}{*}{ Development } & Frequency & $\begin{array}{l}\text { Percentage } \\
(\%)\end{array}$ \\
& Helpful & 209 & 88.56 \\
& Not Sure & 18 & 7.63 \\
& Not Helpful & 9 & 3.81 \\
Access & Easy & 165 & 69.92 \\
& Not Sure & 39 & 16.53 \\
& Not Easy & 32 & 13.56 \\
Content* & Useful & 218 & 92.37 \\
& Not Sure & 18 & 7.63 \\
& Not Useful & 0 & 0.00 \\
\multirow{3}{*}{ Navigate } & Easy & 167 & 70.76 \\
& Not Sure & 41 & 17.37 \\
& Not Easy & 28 & 11.86 \\
\hline
\end{tabular}

* No responses for 'Not Useful'

\section{Learning Objective Review Instrument Results}

Coaches $(n=16)$ and players $(n=209)$ were asked two follow-up questions to detail their positive and negative experiences with the online learning modules. These questions were also the basis for the thematic analysis that was then applied to evaluate the online course with the LORI approach.

The thematic analysis for the question investigating positive experiences of the course gave rise to 14 specific codes from 219 responses (24 coded as none or other), while analysis of the 149 reported negative experiences gave seven codes ( 71 coded as none). These were then mapped onto the LORI for the course (see table 2). The result of the thematic analysis showed that the participants reported more positive experiences than negative experiences (220 vs 149). Positive experiences were also more diverse giving more sub-themes (codes) that matched the LORI themes. 'Difficulty' and 'presentation' were the only shared sub-themes that arose in positive and negative experiences. The following will present the LORI themes and give some examples of the responses to the themes. Any response rates under 5 will not be presented.

\section{Content Quality}

Participants described positive experiences of difficulty as:

"They are straightforward and easy to complete" and

"Easy to complete and we were given time to do it"

while for negative experiences the responses were contrasting:

"Make it easier" and

"I thought the course was good, because it [sic] videos, written text, and games, it could of [sic] made the questions harder as they were quite easy".

Participants also reported that they were able to positively relate to the content:

"I liked that the course was all relevant to the type of things I'll have to deal with or may come across" and

"Very relevant and lots of useful information that will help adjust to life as a scholar both on and off the pitch".

This theme received the most responses $(24 \%$ of total responses) where more positive experiences were reported than negative $(28 \%$ vs. $18 \%)$. These results and diverse responses given for negative experiences indicate that the content has variation.

\section{Learning Goal Alignment}

Positive experiences for this theme came from the sub-themes' learning outcomes (learning goals) and situations (activities), while the negative experiences were focused more on preferences (learner characteristics).

Examples of learning outcomes include:

"The content was relatable to what happens in the professional game. The course provides a platform to highlight ways to deal with scenarios that will occur during your scholarship and professional football career. The ability to complete sections allowed the opportunity to [sic] chunk learning and enabled focus to be maintained on the key aspects of what is being delivered" and

"It showed me how to cope in different situations and revealed traits [sic] didn't know I had myself".

Participants described situation activities as:

"I liked how realistic it was and how it was based on actual real-life everyday situations that people go through. I also like the game quiz at the end of all of the courses to see how much you remember and whether or not you were paying attention to the information being said as well as the videos" and

"Examples of real-life scenarios which made it easier to understand".

Negative experiences coded for this theme were more a reflection of personal preferences (learner characteristics): 
Table 2: Distribution of Positive and Negative Statements

\begin{tabular}{|c|c|c|c|c|c|c|c|}
\hline LORI Category & $\begin{array}{l}\text { Positive } \\
\text { experiences } \\
\text { codes }(234) \\
\end{array}$ & $\begin{array}{l}\text { Number of } \\
\text { statements }\end{array}$ & $\begin{array}{l}\text { Total POS } \\
\%\end{array}$ & $\begin{array}{l}\text { Negative } \\
\text { experiences } \\
\text { codes }(220) \\
\end{array}$ & $\begin{array}{l}\text { Number of } \\
\text { statements }\end{array}$ & $\begin{array}{l}\text { Total NEG } \\
\%\end{array}$ & $\begin{array}{l}\text { \% of Total } \\
\text { Response } \\
(454)\end{array}$ \\
\hline \multirow{2}{*}{ Content Quality } & Difficulty & 54 & \multirow[t]{2}{*}{.28} & \multirow[t]{2}{*}{ Difficulty } & \multirow[t]{2}{*}{42} & \multirow[t]{2}{*}{.18} & \multirow[t]{2}{*}{.24} \\
\hline & Relate & 11 & & & & & \\
\hline \multirow{2}{*}{ Learning Goal Alignment } & Learning & 30 & \multirow[t]{2}{*}{.19} & \multirow[t]{2}{*}{ Preference } & \multirow[t]{2}{*}{31} & \multirow[t]{2}{*}{.13} & \multirow[t]{2}{*}{.17} \\
\hline & Situations & 14 & & & & & \\
\hline \multirow{2}{*}{$\begin{array}{l}\text { Feedback } \\
\text { Adaptation }\end{array}$} & Knowledge & 27 & \multirow[t]{2}{*}{.20} & \multirow[t]{2}{*}{ Time } & \multirow[t]{2}{*}{42} & \multirow[t]{2}{*}{.18} & \multirow[t]{2}{*}{.19} \\
\hline & Reflection & 19 & & & & & \\
\hline \multirow{3}{*}{ Motivation } & Helpful & 12 & .11 & \multirow{3}{*}{$\begin{array}{l}\text { No identified } \\
\text { themes }\end{array}$} & & & \multirow[t]{3}{*}{.06} \\
\hline & Competitive & 11 & & & & & \\
\hline & Fun & 3 & & & & & \\
\hline \multirow{2}{*}{ Presentation Design } & Materials & 19 & \multirow[t]{2}{*}{.09} & \multirow[b]{2}{*}{ Presentation } & \multirow[b]{2}{*}{4} & .02 & \multirow[t]{2}{*}{.06} \\
\hline & Presentation & 2 & & & & .02 & \\
\hline Interaction Usability & Interactive & 8 & .03 & $\begin{array}{c}\text { More } \\
\text { interactive }\end{array}$ & 14 & .06 & .05 \\
\hline \multirow[t]{3}{*}{ Reusability } & $\begin{array}{l}\text { No identified } \\
\text { themes }\end{array}$ & & & $\begin{array}{l}\text { Technical } \\
\text { difficulties }\end{array}$ & 30 & .14 & .07 \\
\hline & None & 20 & .09 & None & 71 & .32 & .21 \\
\hline & Other & 4 & .02 & & & & .01 \\
\hline
\end{tabular}

"Use more of a variety of players' experiences rather than just team or just one player's position. For instance, use a GK [goalkeeper] to understand what his experiences are like as they would be different to a striker's" and

"More opportunities to relate the topics to your own performance or feelings".

This theme ranked third overall (17\%) for the LORI.

\section{Feedback and Adaptation}

Positive experience sub-themes that arose for this theme were knowledge (adaptive content) and reflection (feedback). Participants described their experiences of gaining knowledge:

"The small videos allowed you to really get a grip on the topic as well as views from other professional footballers" and

"The course broke down many subjects that help us become professional footballers".

The course also helped with reflective behaviours (feedback):

"How it gave me a better understanding on how to [sic] I can improve off the pitch to allow me to improve on the pitch" and

"The way it made me realise there is [sic] a lot of things in football and to do with football. Not just the game itself".

Negative experiences were all associated with time-related aspects (adaptive content), where only participants from the players' group $(n=42)$ expressed that the course was too long. The Feedback and Adaptation theme was the second most commented-on LORI theme (19\%) and was balanced between positive and negative experiences (20\% vs $18 \%$ ), although only the players had issues with the length of the course.

Motivation

Experiences for this theme were only positive, as no negative experiences to motivation were reported. Three sub-themes (helpful, competitive, fun) appeared.

Statements that supported the sub-theme helpful (stimulate interest) included:

"The course being open and helpful to the reality of competitive football" and

"How it helps me as a player and a person".

Participants also commented on the competition aspect: "...the questions at the end when you played against other people"

while the other comments were all similar in identifying the quiz at the end of the course as an activity that they found positive.

The fun sub-theme only had three responses but all indicated the course was fun.

This theme received only $6 \%$ of the total comments.

\section{Presentation Design, Interaction Usability, and} Reusability

These three LORI themes are presented together due to their low total amounts of experiences $(6 \%, 5 \%, 7 \%$, respectively) in the more technical aspects. Positive experiences for presentation design were mostly focused on the materials the course used. Comments such as:

"The videos allowed us to gain an insight on [sic] what the elite players think" and

"The videos gave me good insight to the right and wrong actions in football" 
demonstrate that the videos used were good examples of football behaviours.

Interaction usability received more negative comments (14) than positive (8). The participants' comments highlighted the need for more interaction and fewer videos, or indicated that the content was uninteresting, whereas the positive comments supported the use of videos.

The reusability theme received the most comments of the three technical aspects (7\% overall) and all were negative experiences that were focused on technical difficulties (30 comments in total). Participants reported problems in, among others, access to the course, content interface, navigation, and information.

\section{Other responses}

No response $(n=91)$ or responses classified as other $(n=4)$ made up $21 \%$ of all responses, and this category was the second-largest when taken together with the LORI themes, after Content Quality. There were more no responses for negative experiences than positive experiences ( 71 vs 20 ). This high percentage may be due to questions being vaguely formulated or difficult to respond to due to labelling errors.

Table 3: Negative Codes

\begin{tabular}{lcc}
\hline Code & $\begin{array}{c}\text { Easy } \\
(\mathbf{8 0} \%)\end{array}$ & $\begin{array}{c}\text { Not Sure/ Not Easy } \\
(\mathbf{2 0} \%)\end{array}$ \\
\hline All & 1 & 0 \\
Difficult & 41 & 0 \\
Interactive & 7 & 0 \\
None & 71 & 0 \\
Preference & 31 & 0 \\
Presentation & 10 & 0 \\
Technical & 31 & 0 \\
difficulties & 2 & 38 \\
Time & 0 & 4 \\
Materials & 194 & 42 \\
\hline Total & &
\end{tabular}

\section{Quantitative findings}

The results show that, in general, the course was positively received but that almost $20 \%$ did not have a positive experience ( $n=42$; Negative group). Participants who answered either 'not sure' or 'not easy/helpful' were almost four times more likely to give negative comments $(O R=3.90, p<.001)$ but did not differ in giving positive comments $(O R=0.152, p=0.763)$. They also only reported that the course was too long (38 of 42 participants; $X^{2}=223.01, d f=8, p<0.01$, Kramer's $V=0.972$ ) where the other four participants commented that there were too many videos. When taken together with the LORI thematic analysis, certain issues do arise. For participants who rated the course as 'easy/helpful' (positive group), their negative experiences focused on educational aspects related to the content being too difficult or to easy, or that it did not match their preferences, or that they had experienced technical difficulties, while the negative group mainly experienced the course as being too long (table 3 ). For positive comments, the two groups also reported significantly different $\left(X^{2}=209.42, d f=23, p<.001\right.$, Cramer's $V=.944)$. The positive experience group reported comments on all themes of the LORI, while participants in the negative group commented that they could relate to the content and liked the presented situations (content quality) and reflection (feedback; See tables 1 and 2 for distribution).

Table 4: Positive Codes

\begin{tabular}{lcc}
\hline Code & $\begin{array}{c}\text { Easy } \\
(\mathbf{8 0} \%)\end{array}$ & $\begin{array}{c}\text { Not Sure/ Not Easy } \\
(\mathbf{2 0} \%)\end{array}$ \\
\hline Easy & 2 & 0 \\
Competitive & 12 & 0 \\
Easy & 52 & 0 \\
Enjoyment & 3 & 0 \\
Helpful & 12 & 0 \\
Interactive & 8 & 0 \\
Knowledge & 28 & 0 \\
Learning & 30 & 0 \\
Materials & 19 & 0 \\
None & 20 & 0 \\
Presentation & 2 & 1 \\
Reflection & 5 & 14 \\
Relate & 0 & 11 \\
Situation & 0 & 14 \\
Topics & 0 & 1 \\
Time & 1 & 0 \\
\hline Total & 194 & 41 \\
\hline
\end{tabular}

\section{Discussion}

The aim of this study was to examine the efficacy of an online course designed to help athletes cope with the inherent stressors within football, which can negatively impact on the experience of players within the sport (Sarkar \& Fletcher, 2014). The course aimed to improve players' education into the coping mechanisms available to them to help alleviate the negative effects of stressors associated with the sport and improve mental health and psychological performance. In addition, the course aimed to encourage a reduction in the prevalence of stigmatised attitudes towards help-seeking and psychoeducation. Although it is recognised that players have a tendency not to engage in help-seeking behaviours (Steinfeldt \& Steinfeldt, 2012), there has recently been an increase in players asking the PFA for help with mental health issues (PFA, 2021). Considering these two factors, the current research recognises the importance of endeavoring to find ways of helping players to cope with the mental implications of life as a professional football player which is paramount to improving their mental well-being.

Having recognised the importance of providing players with psychological coping strategies, the implementation of this course was intended to diminish the mental health concerns associated with the many stressors experienced by players transitioning into elite sport and especially, in this instance, within football, which is recognised as a challenging environment (Nesti, 2011; Pain \& Harwood, 2004) specifically at this level (Rice et al., 2016; Sheehan et al., 2018). As such, the course was 
generally well received, however, there is room for improvement. There were more positive feedback statements than negative (210 vs 159 ). Based on the LORI framework and not counting the 'no response' response, which made up $32 \%$ of all negative responses, almost all of the negative feedback statements (145 out of 159) were due to the online course being too difficult, time consuming, or experiencing technical difficulties, whereas positive feedback was more varied, motivating and promoting learning goals.

Using the LORI framework (Nesbit et al., 2004) as a means of measuring the efficacy of the course, it was found that although the participants reported more positive experiences than negative experiences, the number of negative experiences is still too high. Twenty percent of the participants did not have good experiences with the online course. Considering that this is a group of learners engaged in goal-directed behaviour, i.e. honing their professional skills, it would be expected that they are more likely to perceive the activities positively, which in turn should improve learning (Pekrun, 2006). The negative experiences seemed to center around the feedback and adaptation element of the LORI framework, with specific reference to the length of the course. The course takes an average of 2 hours to complete, however, and therefore clarity is needed as to why $20 \%$ of the participants considered it too long. It is not completely clear what the participants meant by 'too long' as perhaps it was the length of time during one sitting which promoted such comments. As such, the course could be completed over several sittings and it would be useful to know how it compares with the length of other comparable courses taken by footballers.

Compressed courses are more likely to be completed (Sheldon \& Durdella, 2009); however, athletes in sport that requires decision-making skills to cope with continual change during the game tend to have the ability to maintain attention (Verburgh et al., 2014), and successful footballers have enhanced cognitive ability (Vestberg et al., 2017). Therefore, the compressed nature of the course, the proposed flexibility in allowing participants to complete the course at their own pace, and the expected ability of footballers to maintain concentration, the length of course that $20 \%$ of the participants reported as too long, should not be problematic. This issue could be overcome by providing options regarding the pacing of the course in terms of the release of modules at staged intervals. There is also the option of making the course layered in terms of depth of content, with an acknowledgment for participants, perhaps in terms of graded certification for those who attempt a greater depth of learning.

Negative experiences within the Content Quality of the LORI framework were represented by technical difficulties. Going forward, technical difficulties need to be resolved to avoid negating any benefits of online delivery. Solving the issue of technical difficulties experienced by participants is particularly important since such obstacles will not only increase dissatisfaction but can impair learning ability and potentially increase course attrition rates (Sitzmann et al., 2010).

Content quality also had mixed results. Some participants were positive about the challenge level of the course whilst others found it too hard. Those who had a positive experience found the course relevant, the information useful and enjoyed the variation of the content. Specifically, scenario-based learning and the interactive nature of the course seemed to resonate well with the majority of the participants, complimenting the previous findings of Hursen and Fasli (2017), albeit their research was on an older cohort of teachers as opposed to adolescents receiving the teaching. The coaches in the current study, similarly to the teachers in the Hursen and Fasli study, concurred with the effectiveness of the scenario-based learning implemented in this course.

Combined, these findings show how the psychoeducation delivery combined with the scenariobased learning highlight aspects of James \& Pollards (2011) principles for effective pedagogy. This course provided competence development that was directed at both their football performance but also their wellbeing. This was done by presenting research, case studies and real-life examples, while having access to professionals, both performance and mental health who could facilitate their learning processes. The only principles that were not met were the perceived difficulties of the assessments for some players (principle \#5) and the technical difficulties caused engagement problems (principle \#6). Otherwise, the positive feedback statements show support to all the principles except the demand for policy frameworks (principle \#10).

\section{Limitations}

There are some limitations of this study. Firstly, it would have been useful to compare the results of the current course with other similar courses offered to athletes. The response rate to some questions was low indicating flaws in the data collection element. Forced responses would have helped eliminate the lack of responses to some questions. Also, the combining of Likert scale terminology 'helpful/easy' and 'not helpful/easy' and having only 3 labels for answers could have different meanings when interpreted by the participants leading to response errors or not having enough nuance to give correct responses. Future research might look at designing Likert Scale responses; this means of data collection is specifically pertinent, as whilst the qualitative element was useful for an initial study, in order to fully generalise and understand the efficacy of the course, a quantitative design with a larger sample size is necessary. The qualitative study has provided an understanding of the experiences of both the coach and athletes whilst taking the course and this understanding can form the basis of a larger quantitative design. The LORI instrument provides a suitable framework of assessment and provides the research with suitable action point criteria to enable recommendations for future improvements to be made within the course design to encourage even higher levels of motivation and user satisfaction. Lastly, twenty percent of the respondents were not sure of the efficiency of the course. While the results showed trends, a large portion of participants may have not benefitted from the on-line course.

\section{Conclusion}

The aim of this research, which was to understand the participants' perception of the efficacy of the course, has been achieved. The course was generally found to be effective, similar to observations by Henriksen et al. (2020), who also found educational courses to be an effective, viable way of increasing the ability to cope with the stressors which can lead to poor mental adjustment. However, it is a work in progress and must be subject to continual review and refinement, in a continuous attempt to meet the needs of its users, and via education to provide them with the skills and means to build strategies to effectively cope and surmount the various stressors that accompany the transition into elite sport. The success of the course is reflected in the fact that the PFA has shown interst in the commissioing of a second course to compliment this one, which might be undertaken by participants approaching the end of their scholarship training and will be designed using the psychoeducational 
Four Pillars model, to introduce the PFA transition process and themes around player transition, education and athletic identity. Continued feedback from both courses and future research will contribute to the on-going attempt to generally improve the course, user engagement and perceived course efficacy.
Akpinar, Y. (2009). validation of a learning object Review Instrument: Relationship between Ratings of learning objects and Actual learning outcomes. International Journal of Doctoral Studies, 4(4), 291-302.

Blackburn, G. (2015). Innovative eLearning: Technology shaping contemporary problem based learning: A cross-case analysis. Journal of University Teaching \& Learning Practice, 12(2), 5.

Blakelock, D. J., Chen, M. A., \& Prescott, T. (2016). Psychological distress in elite adolescent soccer players following deselection. Journal of Clinical Sport Psychology, 10(1), 59-77.

Braun, V., \& Clarke, V. (2006). Using thematic analysis in psychology. Qualitative research in psychology, 3(2), 77101.

Brown, G., \& Potrac, P. (2009). 'You've not made the grade, son': de-selection and identity disruption in elite level youth football. Soccer \& Society, 10(2), 143-159.

Brownrigg, A., Burr, V., Locke, A., \& Bridger, A. J. (2012). You don't know what's around the corner: A qualitative study of professional footballers in England facing careertransition. Qualitative Methods in Psychology Bulletin(14).

Creswell, J. W., \& Báez, J. C. (2020). 30 essential skills for the qualitative researcher. Sage Publications.

Crocker, P. R. (1992). Managing stress by competitive athletes: Ways of coping. International journal of sport psychology.

Donohue, B., Gavrilova, Y., Galante, M., Gavrilova, E., Loughran, T., Scott, J., Chow, G., Plant, C. P., \& Allen, D. N. (2018). Controlled evaluation of an optimization approach to mental health and sport performance. Journal of Clinical Sport Psychology, 12(2), 234-267.

Flick, U. (2007). Qualitative research designs. Designing qualitative research, 109-114.

Flick, U. (2018). An introduction to qualitative research. sage.

Francescucci, A., \& Rohani, L. (2019). Exclusively synchronous online (VIRI) learning: The impact on student performance and engagement outcomes. Journal of marketing Education, 41(1), 60-69.

Fraser-Thomas, J., \& Côté, J. (2009). Understanding adolescents' positive and negative developmental experiences in sport. The sport psychologist, 23(1), 3-23.

Gearing, B. (1999). Narratives of identity among former professional footballers in the United Kingdom. Journal of Aging Studies, 13(1), 43-58.

Gorczynski, P., Gibson, K., Thelwell, R., Papathomas, A., Harwood, C., \& Kinnafick, F. (2019). The BASES expert statement on mental health literacy in elite sport. The Sport and Exercise Scientist, 59, 6-7.

Gould, D., Eklund, R. C., \& Jackson, S. A. (1993). Coping strategies used by US Olympic wrestlers. Research quarterly for Exercise and Sport, 64(1), 83-93.

Gouttebarge, V., Aoki, H., \& Kerkhoffs, G. M. (2016). Prevalence and determinants of symptoms related to mental disorders in retired male professional footballers. J Sports Med Phys Fitness, 56(5), 648-654.

Henriksen, K., Schinke, R., Moesch, K., McCann, S., Parham, W. D., Larsen, C. H., \& Terry, P. (2020). Consensus statement on improving the mental health of high performance athletes. International journal of sport and exercise psychology, 18(5), 553-560.

Hilsdon, J. (2014). Peer learning for change in higher education. Innovations in Education and Teaching International, 51(3), 244-254.

Hollis, C., Falconer, C. J., Martin, J. L., Whittington, C., Stockton, S., Glazebrook, C., \& Davies, E. B. (2017). Annual Research Review: Digital health interventions for children and young people with mental health problems-a systematic and meta-review. Journal of Child Psychology and Psychiatry, 58(4), 474-503.
Hursen, C., \& Fasli, F. G. (2017). Investigating the Efficiency of Scenario Based Learning and Reflective Learning Approaches in Teacher Education. European Journal of Contemporary Education, 6(2), 264-279.

James, M., \& Pollard, A. (2011). TLRP's ten principles for effective pedagogy: rationale, development, evidence, argument and impact. Research Papers in Education, 26(3), 275328.

Jorm, A. F. (2000). Mental health literacy: Public knowledge and beliefs about mental disorders. The British Journal of Psychiatry, 177(5), 396-401.

Kolb, A. Y., \& Kolb, D. A. (2009). The learning way: Meta-cognitive aspects of experiential learning. Simulation \& gaming, 40(3), 297-327.

Krane, V., Snow, J., \& Greenleaf, C. A. (1997). Reaching for gold and the price of glory: A motivational case study of an elite gymnast. The sport psychologist, 11(1), 53-71.

Leacock, T. L., \& Nesbit, J. C. (2007). A framework for evaluating the quality of multimedia learning resources. Journal of Educational Technology \& Society, 10(2), 44-59.

MacIntyre, T. E., Jones, M., Brewer, B. W., Van Raalte, J., O'Shea, D., \& McCarthy, P. J. (2017). Mental health challenges in elite sport: Balancing risk with reward. Frontiers in Psychology, 8, 1892.

Miller, P. K., Cronin, C., \& Baker, G. (2015). Nurture, nature and some very dubious social skills: An interpretative phenomenological analysis of talent identification practices in elite English youth soccer. Qualitative Research in Sport, Exercise and Health, 7(5), 642-662.

Mitchell, T. O., Nesti, M., Richardson, D., Midgley, A. W., Eubank, M., \& Littlewood, M. (2014). Exploring athletic identity in elite-level English youth football: a cross-sectional approach. Journal of sports sciences, 32(13), 1294-1299.

Nesbit, J., Belfer, K., \& Leacock, T. (2004). LORI 1.5: Learning object review instrument. Retrieved July, 26, 2006.

Nesti, M. (2011). Sport psychology and spirit in professional football. Theology, ethics and transcendence in sports, 149-162.

Pain, M. A., \& Harwood, C. G. (2004). Knowledge and perceptions of sport psychology within English soccer. Journal of sports sciences, 22(9), 813-826.

Pekrun, R. (2006). The control-value theory of achievement emotions: Assumptions, corollaries, and implications for educational research and practice. Educational psychology review, 18(4), 315-341.

PFA, T. (2021). ThePFA.com. https://www. thepfa.com/

Reiter, R. (1987). A theory of diagnosis from first principles. Artificial intelligence, 32(1), 57-95.

Rice, S. M., Purcell, R., De Silva, S., Mawren, D., McGorry, P. D., \& Parker, A. G. (2016). The mental health of elite athletes: a narrative systematic review. Sports medicine, 46(9), 1333-1353.

Sarkar, M., \& Fletcher, D. (2014). Psychological resilience in sport performers: a review of stressors and protective factors. Journal of sports sciences, 32(15), 1419-1434.

Schinke, R. J., Stambulova, N. B., Si, G., \& Moore, Z. (2018). International society of sport psychology position stand: Athletes' mental health, performance, and development. International journal of sport and exercise psychology, $16(6), 622-639$.

Sheehan, R. B., Herring, M. P., \& Campbell, M. J. (2018). Associations between motivation and mental health in sport: a test of the hierarchical model of intrinsic and extrinsic motivation. Frontiers in Psychology, 9, 707.

Sheldon, C. Q., \& Durdella, N. R. (2009). Success rates for students taking compressed and regular length developmental courses in the community college. Community College Journal of Research and Practice, 34(1-2), 39-54.

Sitzmann, T., Ely, K., Bell, B. S., \& Bauer, K. N. (2010). The effects of technical difficulties on learning and attrition during 
online training. Journal of Experimental Psychology: Applied, 16(3), 281.

Smith, R. E., \& Smoll, F. L. (2002). Youth sports as a behavior setting for psychosocial interventions.

Steinfeldt, J. A., \& Steinfeldt, M. C. (2012). Profile of masculine norms and help-seeking stigma in college football. Sport, Exercise, and Performance Psychology, 1(1), 58.

Sundgot-Borgen, J., \& Torstveit, M. K. (2004). Prevalence of eating disorders in elite athletes is higher than in the general population. Clinical journal of sport medicine, 14(1), 2532.

Taylor, J., \& Hulme, J. (2015). Introducing a compendium of psychological literacy case studies: Reflections on psychological literacy in practice. Psychology Teaching Review, 21(2), 25-34.

Terry, G., Hayfield, N., Clarke, V., \& Braun, V. (2017). Thematic analysis. The Sage handbook of qualitative research in psychology, 17-37.

Tracy, S. J. (2010). Qualitative quality: Eight "big-tent" criteria for excellent qualitative research. Qualitative inquiry, $16(10), 837-851$

Vargo, J., Nesbit, J. C., Belfer, K., \& Archambault, A. (2003). Learning object evaluation: computer-mediated collaboration and inter-rater reliability. International Journal of Computers and Applications, 25(3), 198-205.

Verburgh, L., Scherder, E. J., van Lange, P. A., \& Oosterlaan, J. (2014). Executive functioning in highly talented soccer players. PloS one, 9(3), e91254.

Vestberg, T., Reinebo, G., Maurex, L., Ingvar, M., \& Petrovic, P. (2017). Core executive functions are associated with success in young elite soccer players. PloS one, 12(2), e0170845.

Wallston, K. A., \& Wallston, B. S. (1981). Health locus of control scales. Research with the locus of control construct, 1 , 189-243.

Weick, K. E. (2007). The generative properties of richness. Academy of management journal, 50(1), 14-19. 